\title{
HEDONIC PRICES AND IMPLICIT MARKETS: \\ ESTIMATING MARGINAL WILLINGNESS TO PAY FOR DIFFERENTIATED PRODUCTS WITHOUT INSTRUMENTAL VARIABLES
}

\author{
Kelly C. Bishop \\ Christopher Timmins \\ Working Paper 17611 \\ http://www.nber.org/papers/w17611 \\ NATIONAL BUREAU OF ECONOMIC RESEARCH \\ 1050 Massachusetts Avenue \\ Cambridge, MA 02138 \\ November 2011
}

\begin{abstract}
We thank the seminar/conference participants at the AERE/ASSA Annual Meetings, Camp Resources, Iowa State University, Montana State University, Syracuse University, the Triangle Resource and Environmental Economics Workshop, the UEA/RSAI Annual Meetings, the University of Wisconsin, the University of Stirling, the University of Aberdeen, LSE Center for Economic Performance, and Econometric Society Summer Meetings for their helpful comments and suggestions. The views expressed herein are those of the authors and do not necessarily reflect the views of the National Bureau of Economic Research.
\end{abstract}

NBER working papers are circulated for discussion and comment purposes. They have not been peerreviewed or been subject to the review by the NBER Board of Directors that accompanies official NBER publications.

(C) 2011 by Kelly C. Bishop and Christopher Timmins. All rights reserved. Short sections of text, not to exceed two paragraphs, may be quoted without explicit permission provided that full credit, including (c) notice, is given to the source. 
Hedonic Prices and Implicit Markets: Estimating Marginal Willingness to Pay for Differentiated Products Without Instrumental Variables

Kelly C. Bishop and Christopher Timmins

NBER Working Paper No. 17611

November 2011

JEL No. Q51,R0

\begin{abstract}
The hedonic model of Rosen (1974) has become a workhorse for valuing the characteristics of differentiated products despite a number of well-documented econometric problems. For example, Bartik (1987) and Epple (1987) each describe a source of endogeneity in the second stage of Rosen's procedure that has proven difficult to overcome. In this paper, we propose a new approach for recovering the marginal willingness-to-pay function that altogether avoids these endogeneity problems. Applying this estimator to data on large changes in violent crime rates, we find that marginal willingness-to-pay increases by ten cents with each additional violent crime per 100,000 residents.
\end{abstract}

Kelly C. Bishop

Olin Business School

Washington University in St. Louis

Box 1133, 1 Brookings Drive

St. Louis, MO 63130

kbishop@wustl.edu

Christopher Timmins

Department of Economics

Duke University

209 Social Sciences Building

P.O. Box 90097

Durham, NC 27708-0097

and NBER

christopher.timmins@duke.edu 


\section{Introduction}

Dating back to the work of Court (1939), Grilliches (1961), and Lancaster (1966), hedonic techniques have been used to estimate the implicit prices associated with the attributes of differentiated products. Rosen's (1974) seminal work proposed a theoretical structure for the hedonic regression and a two-stage procedure for the recovery of marginal willingness-topay (MWTP) functions of heterogeneous individuals for the characteristics of differentiated products. Importantly, his two-stage approach allowed for two sources of preference heterogeneity: individuals' MWTP functions could differ with $(i)$ their individual attributes and $(i i)$ the quantity of the product attribute that they consume. The latter is particularly important when considering non-marginal policy changes (i.e., any change that is large enough to alter the individual's willingness to pay at the margin). The two-stage procedure suggested by Rosen (and further developed by subsequent authors) uses variation in implicit prices (obtained either by employing data from multiple markets or by allowing for non-linearity in the hedonic price function) to identify the MWTP function.

With Rosen (1974) as a backdrop, the property value hedonic model has become the workhorse for valuing local public goods and environmental amenities, despite a number of well-known and well-documented econometric problems. ${ }^{1}$ Our concern in this paper is with an important problem that arises in the second stage of Rosen's two-step procedure. In separate papers, Bartik (1987) and Epple (1987) describe a source of endogeneity that is difficult to overcome using standard exclusion restriction arguments. Specifically, they note that unless the hedonic price function is linear, the hedonic price of a product attribute varies systematically with the quantity consumed. The researcher therefore faces a difficult endogeneity problem in the estimation of Rosen's second stage. Moreover, because of the

\footnotetext{
${ }^{1}$ See Taylor (2003) and Palmquist (2005) for a comprehensive discussion. Some of these problems arise in the first stage of Rosen's two-step procedure; for example, omitted variables that may be correlated with the local attribute of interest. There is a large and growing literature that describes both quasi-experimental and structural solutions to this problem (see Parmeter and Pope (2009) for a discussion).
} 
equilibrium features of the hedonic model, there are very few natural exclusion restrictions that one can use to solve this endogeneity problem. In particular, within-market supply-side shifters - the typical instrument of choice when estimating a demand equation - are not valid in this context. This has generally left researchers to choose from a variety of weak instrument strategies or instruments based on cross-market preference homogeneity assumptions that may be difficult to justify. With a few exceptions, the hedonics literature has subsequently ignored Rosen's second stage, focusing instead on recovering estimates of the hedonic price function and valuing only marginal changes in amenities. ${ }^{2,3}$

In this paper, we propose an estimation procedure for the recovery of the structural parameters underlying the MWTP function that avoids the Bartik-Epple endogeneity problem altogether. We do this by exploiting the relationship between the quantity of the amenity being consumed and the attributes of the individuals doing the consumption. That such a relationship should exist in hedonic equilibrium goes back to the idea of "stratification" found in Ellickson (1971), which became the basis for estimable Tiebout sorting models. ${ }^{4}$ Our proposed method is identified even in a single-market setting, given a flexible representation of the hedonic price function and a parametric representation of the MWTP function. Importantly, our procedure is computationally simple and easy to implement. Moreover, it does not require any more in terms of data or assumptions than does the standard hedonic model.

\footnotetext{
${ }^{2}$ See, for example, Black (1999), Gayer, Hamilton, and Viscusi (2000), Bui and Mayer (2003), Davis (2004), Figlio and Lucas (2004), Chay and Greenstone (2005), Linden and Rockoff (2008), Pope (2008), Greenstone and Gallagher (2008), Bajari, Cooley, Kim, and Timmins (2011), and Gamper-Rabindran, Mastromonaco, and Timmins (2011).

${ }^{3}$ Deacon et al. (1998) noted that "To date no hedonic model with site specific environmental amenities has successfully estimated the second stage marginal willingness to pay function." Since that time, a number of papers have examined the problem of recovering preferences from hedonic estimates. Bajari and Benkard (2005) avoid the Bartik-Epple endogeneity problem by relying on strong parametric assumptions on utility that turn Rosen's second-stage from an estimation problem into a preference-inversion procedure. We report results based on their suggested procedure in our application. Ekeland, Heckman, and Nesheim (2004) provide an alternative approach to recovering MWTP that imposes very little in terms of parametric restrictions, but requires an additive separability assumption in the MWTP specification. Heckman, Matzkin, and Nesheim (2010) illustrate conditions under which non-separable utility functions may be non-parametrically identified (in both single and multiple markets) and propose a non-parametric estimator.

${ }^{4}$ See, for example, Epple, Filimon and Romer (1984), Epple and Romano (1998), Epple and Platt (1998), and Epple and Sieg (1999).
} 
To demonstrate the usefulness of this approach, we implement our estimation procedure using data on large changes in violent crime rates in the San Francisco Bay Metropolitan Area over the period 1994 to 2000. We find that recovering the full MWTP function is economically important; an individual's marginal willingness to pay to avoid an incident of violent crime (measured by cases per 100,000 residents) increases by 10 cents with each additional incident. Non-marginal reductions in crime of the sort seen in San Francisco and the rest of the nation during the 1990s therefore have the potential to significantly affect MWTP. We find that naive estimators, which ignore this effect, yield estimates of total willingness to pay for crime reductions in San Francisco that are significantly biased. Similar problems are likely to arise in other settings where policy changes are not marginal - e.g., air quality, school reform, and hazardous waste site remediation.

This paper proceeds as follows. Section 2 describes the endogeneity problem discussed by Bartik (1987) and Epple (1987) and reiterates the intuition for why the problem has been so difficult to solve with standard exclusion restrictions. Section 3 describes our alternative estimation procedure in detail. Section 4 describes the data used in our application - housing transactions data from the San Francisco Metropolitan Area combined with violent and property crime data from the RAND California Database. Section 5 reports the results of applying our estimator to these data. Section 6 calculates the welfare effects from the actual non-marginal changes in crime faced by a subset of homeowners and compares these welfare effects with those calculated with alternative procedures in the existing literature. Finally, Section 7 concludes. 


\section{Why Has It Been So Difficult To Recover The MWTP Function?}

In their respective 1987 articles, Epple and Bartik each discuss the econometric problems induced by the equilibrium sorting process that underlies the formation of the hedonic price function. In particular, unobserved determinants of tastes affect both the quantity of an amenity that an individual consumes and (if the hedonic price function is not linear) the hedonic price of the attribute. ${ }^{5}$ In a regression like the one described in the second stage of Rosen's two-step procedure, the quantity of the amenity that an individual consumes will therefore be endogenous. Moreover, the exclusion restrictions typically used to estimate a demand system (i.e., using supplier attributes as instruments) will not work because, in addition to affecting the quantity of amenity and the hedonic price paid for it, the unobservable component of preferences also determines the supplier from whom the individual purchases. Supplier attributes, which might naturally be used to trace-out the demand function, are therefore correlated with the unobserved determinants of MWTP because of the sorting process underlying the hedonic equilibrium.

To make these ideas concrete, consider the following simple example which is based on Epple's model. We begin with the quadratic hedonic price function given by:

$$
P\left(Z_{i} ; \beta\right)=\beta_{0}+\beta_{1} Z_{i}+\frac{\beta_{2}}{2} Z_{i}^{2}+\epsilon_{i}
$$

where $i=1, \ldots, N$ indexes houses, $P\left(Z_{i} ; \beta\right)$ measures the price of house $i$, and $Z_{i}$ measures the level of the amenity associated with house $i$ (for the sake of illustration, we ignore other

\footnotetext{
${ }^{5}$ The linear hedonic price function assumes that attributes can be unbundled and repackaged in any combination without affecting their marginal value (e.g., the marginal value of another bedroom is the same regardless of how many bedrooms a house already has). In most empirical settings, this assumption is unrealistic.
} 
amenities and house attributes). For now, we consider data from just a single market, but allow for multi-market data in the following section. The linear price gradient associated with this hedonic price function is:

$$
P^{\prime}\left(Z_{i} ; \beta\right) \equiv \frac{\partial P\left(Z_{i} ; \beta\right)}{\partial Z_{i}}=\beta_{1}+\beta_{2} Z_{i}
$$

where $P^{\prime}\left(Z_{i} ; \beta\right)$ denotes the implicit price of $Z_{i}$.

The second stage of Rosen's procedure seeks to recover the coefficients of demand (or marginal willingness to pay) and supply (or marginal willingness to accept) functions for the attribute $Z$ from the first-order conditions of the equilibrium relationships: ${ }^{6}$

$$
P^{\prime}\left(Z_{i}^{d} ; \beta\right)=\alpha_{1}+\alpha_{2} Z_{i}^{d}+\alpha_{3} X_{i}^{d}+\nu_{i}^{d} \quad(\text { demand })
$$

$$
P^{\prime}\left(Z_{i}^{s} ; \beta\right)=\gamma_{1}+\gamma_{2} Z_{i}^{s}+\gamma_{3} X_{i}^{s}+\nu_{i}^{s} \quad \text { (supply) }
$$

where $X_{i}^{d}$ and $X_{i}^{s}$ represent attributes of the buyers and sellers of house $i$, respectively. $\nu_{i}^{d}$ and $\nu_{i}^{s}$ similarly represent unobserved idiosyncratic shocks to tastes and marginal costs.

The problem we consider in this paper arises from the fact that $Z_{i}^{d}$ must necessarily be correlated with $\nu_{i}^{d}$ because of the hedonic sorting process. This is easily shown in the following equation. Noting that $Z_{i}=Z_{i}^{d}$ in hedonic equilibrium and combining Equations (2) and (3) yields:

$$
Z_{i}=\frac{1}{\beta_{2}-\alpha_{2}}\left[\left(\alpha_{1}-\beta_{1}\right)+\alpha_{3} X_{i}^{d}+\nu_{i}^{d}\right]
$$

\footnotetext{
${ }^{6}$ This MWTP function is consistent with the underlying indirect utility function given by: $U_{i}=\alpha_{0}+$ $\alpha_{1} Z_{i}^{d}+\frac{1}{2} \alpha_{2}\left(Z_{i}^{d}\right)^{2}+\alpha_{3} X_{i}^{d} Z_{i}^{d}+\nu_{i} Z_{i}^{d}+\left(I_{i}-P\left(Z_{i}^{d} ; \beta\right)\right)$ where $I_{i}$ is the income of household $i$. This marginal willingness to accept function is consistent with the underlying profit function given by: $\left.\Pi_{i}=P\left(Z_{i}^{s} ; \beta\right)\right)-$ $\gamma_{0}-\gamma_{1} Z_{i}^{s}-\frac{1}{2} \gamma_{2}\left(Z_{i}^{s}\right)^{2}-\gamma_{3} X_{i}^{s} Z_{i}^{s}-\nu_{i}^{s} Z_{i}^{s}$.
} 
Equation (5) makes explicit that $Z_{i}$ will be correlated with $\nu_{i}^{d} \cdot{ }^{7}$ Therefore, in order to estimate Equation (3) directly, the literature has sought an instrument for $Z_{i}^{d}$.

The typical approach to estimating demand functions with endogenous quantities uses supply function shifters. The problem with that approach in this context, however, is that hedonic sorting induces a correlation between $\nu_{i}^{d}$ and $X_{i}^{s}$. Put differently, $\nu_{i}^{d}$ determines the supplier from whom individual $i$ purchases, so that $X_{i}^{s}$ cannot be used to instrument for $Z_{i}^{d}$.

In three respective papers, Epple (1987), Bartik (1987), and Kahn and Lang (1988) propose alternative instrumental variables strategies to deal with this problem. Bartik, for example, suggests instrumenting for $Z_{i}^{d}$ with market indicator variables. Kahn and Lang suggest a similar instrument of market indicators interacted with household demographic attributes. The intuition for these strategies is that differences in the distribution of suppliers across markets will provide an exogenous source of variation in the equilibrium quantity of the amenity chosen by each individual. The problem with these approaches is that they require strong assumptions about cross-market preference homogeneity and the instrument may not induce sufficient variation in the endogenous variable. Ekeland, Heckman, and Nesheim (2004) propose an alternative instrumental variables approach to overcome the endogeneity problem. They show that due to the non-linearity of the hedonic model, the conditional expectation of $Z_{i}^{d}$ given $X_{i}^{d}$ may be used to instrument for $Z_{i}^{d}$. This instrumentation strategy does not require assumptions about cross-market preference homogeneity and may be used in a singlemarket setting. Our proposed estimation strategy differs from these previous approaches as we avoid instrumental variables altogether. Our strategy is the subject of Section 3.

\footnotetext{
${ }^{7}$ It is clear that $Z_{i}$ will be correlated with $\nu_{i}^{d}$ even when we allow for data coming from multiple markets.
} 


\section{Model and Estimation}

In this section, we describe an alternative econometric approach, which avoids this difficult endogeneity problem altogether, while not imposing strong assumptions on the shape of preferences. Beginning with Rosen, the traditional approach has been to equate the implicit price of the amenity $Z$ (from the estimation of the hedonic price function) to its marginal benefit (which is a function of $Z$ ) and use the resulting expression as the estimating equation. The majority of the literature following Rosen has retained this framework while proposing corrective strategies to deal with the endogeneity of $Z$. We note that while the first-order conditions for hedonic equilibrium provide a set of equations that will hold in equilibrium, nothing requires us to write the estimating equation in this manner. While this representation does provide an intuitive interpretation of utility maximization, it is the "marginal cost equals marginal benefit" econometric specification itself which has created the endogeneity problem that has plagued this literature for decades.

Returning to the basic structure of the hedonic model, there is no fundamental endogeneity problem. When choosing how much of the amenity $Z$ to consume, individuals take the hedonic price function as given and choose $Z_{i}$ to maximize utility based on their individual preferences. These preferences are determined by a vector of observed individual characteristics, $X_{i}^{d}$, and unobserved taste shifters, $\nu_{i}^{d}$. As $\nu_{i}^{d}$ and $X_{i}^{d}$ are typically assumed to be orthogonal in the hedonic model, we are left with a familiar econometric modeling environment: an endogenous outcome variable, $Z_{i}$, which is a function of a vector of exogenous variables, $X_{i}^{d}$, and an econometric error, $\nu_{i}^{d}$. Intuitively, our approach finds the parameters of the MWTP function that maximize the likelihood of observing each household's chosen $Z_{i}$.

We first consider the case in which a closed-form solution for $Z_{i}$ exists and the estimation approach is intuitive and simple. In the general case of our model, where a closed-form for $Z_{i}$ may not exist, we show that by using a simple change-of-variables technique it is still 
straightforward to compute the likelihood of observing $Z_{i}$. Also in this section, we provide evidence of our estimator's small sample properties with Monte Carlo simulation results.

\subsection{The Simple Model: When a Closed-Form Solution for $Z$ Exists}

In this subsection, we consider a special case of the general model in which $Z_{i}$ may be easily isolated in the first-order condition for utility maximization. While our proposed estimator is applicable to a much richer specification of the model (as discussed in Section 3.2), we present this simplified case first as the estimation strategy is extremely transparent.

Consider the simple, linear-quadratic model where the hedonic price function is given by:

$$
P\left(Z_{i, j} ; \beta\right)=\beta_{0}+\beta_{1, j} Z_{i, j}+\frac{\beta_{2, j}}{2} Z_{i, j}^{2}+\epsilon_{i, j}
$$

and $i$ indexes houses and $j$ indexes markets (defined by space or time). The hedonic price gradient for market $j$ is therefore:

$$
P^{\prime}\left(Z_{i, j} ; \beta\right) \equiv \frac{\partial P\left(Z_{i, j} ; \beta\right)}{\partial Z_{i, j}}=\beta_{1, j}+\beta_{2, j} Z_{i, j}
$$

where $P^{\prime}\left(Z_{i, j} ; \beta\right)$ denotes the implicit price of $Z_{i, j}$.

Specifying the household's indirect utility as:

$$
U\left(Z_{i, j}, X_{i}^{d} ; \alpha\right)=\alpha_{0, j}+\alpha_{1, j} Z_{i, j}+\frac{1}{2} \alpha_{2} Z_{i, j}^{2}+\alpha_{3, j} X_{i}^{d} Z_{i, j}+\nu_{i, j}^{d} Z_{i, j}+\left(I_{i}-P(Z, \epsilon ; \beta)\right)
$$

where $I_{i}$ represents household $i$ 's income, we arrive at the following first-order condition for 
$Z_{i, j}:$

$$
\alpha_{1, j}+\alpha_{2} Z_{i, j}+\alpha_{3, j} X_{i}^{d}+\nu_{i, j}^{d}-\beta_{1, j}-\beta_{2, j} Z_{i, j}=0
$$

The traditional estimation strategy associated with Rosen would first recover an estimate of $\left(\beta_{1, j}+\beta_{2, j} Z_{i, j}\right)$ from the estimated price gradient, isolate this term on the left hand side of Equation (9), and estimate the resulting regression equation (i.e., the MWTP function), treating $\nu_{i, j}^{d}$ as the regression error, in a separate second stage:

$$
\left(\beta_{1, j}+\beta_{2, j} Z_{i, j}\right)=\alpha_{1, j}+\alpha_{2} Z_{i, j}+\alpha_{3, j} X_{i}^{d}+\nu_{i, j}^{d}
$$

Our approach is to alternatively rearrange Equation (9) such that the single endogenous variable, $Z_{i, j}$, is isolated on the left:

$$
Z_{i, j}=\left(\frac{\alpha_{1, j}-\beta_{1, j}}{\beta_{2, j}-\alpha_{2}}\right)+\left(\frac{\alpha_{3, j}}{\beta_{2, j}-\alpha_{2}}\right) X_{i}^{d}+\left(\frac{1}{\beta_{2, j}-\alpha_{2}}\right) \nu_{i, j}^{d}
$$

Equation (11) describes how the consumption of the amenity $Z$ varies with observable household characteristics, $X_{i}^{d}$, unobservable preference shocks, $\nu_{i, j}^{d}$, and parameters of the hedonic price function, $\left\{\beta_{1, j}, \beta_{2, j}\right\}$. This equation contains all of the information necessary to recover the parameters describing individual preferences, $\left\{\alpha_{1, j}, \alpha_{2}, \alpha_{3, j}, \sigma\right\}$. Using hats to indicate that $\left\{\widehat{\beta_{1, j}}, \widehat{\beta_{2, j}}\right\}$ are known from the first-stage estimation of the hedonic price function, we may write:

$$
Z_{i, j}=\left(\frac{\alpha_{1, j}-\widehat{\beta_{1, j}}}{\widehat{\beta_{2, j}}-\alpha_{2}}\right)+\left(\frac{\alpha_{3, j}}{\widehat{\beta_{2, j}}-\alpha_{2}}\right) X_{i}^{d}+\left(\frac{1}{\widehat{\beta_{2, j}}-\alpha_{2}}\right) \nu_{i, j}^{d}
$$

Making the distributional assumption that $\nu_{i, j}^{d} \sim N\left(0, \sigma^{2}\right), Z_{i, j}$ is then distributed nor- 
mally with mean $\left.\left(\left(\frac{\alpha_{1, j}-\widehat{\beta_{1, j}}}{\widehat{\beta_{2, j}-\alpha_{2}}}\right)+\left(\frac{\alpha_{3, j}}{\widehat{\beta_{2, j}-\alpha_{2}}}\right) X_{i}^{d}\right)\right)$ and standard deviation $\left(\frac{\sigma}{\beta_{2, j}-\alpha_{2}}\right)$. This reveals a straightforward Maximum Likelihood approach for estimating the remaining parameters. ${ }^{8}$ In particular, we find the vector of parameters, $\left\{\alpha_{1, j}, \alpha_{2}, \alpha_{3, j}, \sigma\right\}$, that maximizes the likelihood of the observed vector $\left\{Z_{i, j}\right\}_{i=1}^{N}$. This likelihood is given by $\Pi_{i=1}^{N} \ell\left(Z_{i, j}, X_{i}^{d} ; \alpha, \sigma\right)$ where:

$$
\ell\left(Z_{i, j}, X_{i}^{d} ; \alpha, \sigma\right)=\frac{1}{\left(\frac{\sigma}{\widehat{\beta_{2, j}}-\alpha_{2}}\right) \sqrt{2 \pi}} \exp \left\{-\frac{1}{2\left(\frac{\sigma}{\widehat{\beta_{2, j}-\alpha_{2}}}\right)^{2}}\left(Z_{i, j}-\left(\left(\frac{\alpha_{1, j}-\widehat{\beta_{1, j}}}{\widehat{\beta_{2, j}}-\alpha_{2}}\right)+\left(\frac{\alpha_{3, j}}{\widehat{\beta_{2, j}}-\alpha_{2}}\right) X_{i}^{d}\right)\right)^{2}\right\}
$$

\subsubsection{Indirect Least Squares}

It is worth considering the very special case of this model when estimation is particularly straightforward: the case where the structural parameters may be recovered using a leastsquares estimation.

As an example, consider the specification above with exactly two markets. In this case, Equation (12) may be estimated using an extremely transparent indirect least squares (ILS) procedure. With the same number of equations as unknown structural parameters, ${ }^{9}$ it becomes a simple matter to recover the structural parameters $\left\{\alpha_{1, j}, \alpha_{2}, \alpha_{3, j}, \sigma\right\}$ from the reduced-form parameters $\left\{\theta_{0, j}, \theta_{1, j}, \sigma_{u, j}\right\}$ (which are recovered using OLS for each market $j$ ) by exploiting the unique mapping between the two sets:

$$
Z_{i, j}=\underbrace{\left(\frac{\alpha_{1, j}-\widehat{\beta_{1, j}}}{\widehat{\beta_{2, j}}-\alpha_{2}}\right)}_{\theta_{0, j}}+\underbrace{\left(\frac{\alpha_{3, j}}{\widehat{\beta_{2, j}}-\alpha_{2}}\right)}_{\theta_{1, j}} X_{i}^{d}+\underbrace{\left(\frac{1}{\widehat{\beta_{2, j}}-\alpha_{2}}\right) \nu_{i, j}^{d}}_{u_{i, j}}
$$

\footnotetext{
${ }^{8}$ Kahn and Lang (1988) suggest estimating a restricted version of Equation (12) via non-linear least squares. However, their estimator requires the strong cross-market homogeneity assumption that all of the utility parameters are constant across markets. Additionally, their proposed estimator is only applicable for the subset of cases where a closed-form solution for $\mathrm{Z}$ exists and does not generalize to the cases we present in Section 3.2 .

${ }^{9}$ Let $L$ denote the number of elements in $X$ and $J$ denote the number of markets. The reduced-form estimation returns $(J *(L+1)+J)$ parameters. The number of structural parameters in Equation (12) is $(J *(L+1)+2)$. Therefore, for $J=1$, this model is underidentified (given the linear price gradient). For $J=2$, it is exactly identified. For $J \geq 3$, the model is overidentified.
} 
With more than two markets, one could add richer heterogeneity to the MWTP function (e.g., by parameterizing either the slope of the MWTP function or the variance of $\nu$ ) in order to take advantage of all available information. ${ }^{10}$

\subsection{The General Model: When a Closed-Form Solution for $Z$ May Not Exist}

We now consider a more general form of the model, in which we do not rely on finding a closed-form solution for $Z_{i, j}$. The lack of a closed-form solution will be the case for most non-linear gradient specifications (including the log-linear gradient specification that we use in our application in Section 5). ${ }^{11}$ In this case, we are still able to estimate the model using Maximum Likelihood with a simple change-of-variables technique.

Consider first the case where $\nu_{i, j}^{d}$ is an additively-separable error that enters households' linear MWTP functions and does not enter the hedonic price function. In this case, finding a closed-form solution for $\nu_{i, j}^{d}$ is trivial. We show that by employing a basic change of variables (from $Z$ to $\nu^{d}$ ), a closed-form solution for $\nu_{i, j}^{d}$ is sufficient for forming the likelihood of observing $Z_{i, j}$

In the following example, we impose no parametric assumption on the price function, $P\left(Z_{i, j} ; \beta\right)$, and show how it may no longer be possible to rearrange the first-order condition

\footnotetext{
${ }^{10}$ One could also use this additional information with a more general estimation strategy to overidentify the model's parameters.

${ }^{11}$ As a general rule, one should not expect the hedonic price gradient to be linear. Additionally, specifying the MWTP to be linear is not inconsistent with a nonlinear price gradient in equilibrium; as clearly demonstrated by Ekeland, Heckman, and Nesheim (2004), a linear MWTP function alone does not imply a linear price gradient. For the equilibrium price gradient to be linear (with demand- and supply-side heterogeneity), it would not only require that consumers have a perfectly linear MWTP function, but also that suppliers have a perfectly linear marginal willingness-to-accept function and that shocks to both preferences and profits are exactly normal. A key insight of the Ekeland, Heckman, and Nesheim paper is that very minor perturbations of any of these conditions will lead to substantial non-linearity in the resulting equilibrium price gradient.
} 
to isolate $Z_{i, j}$ :

$$
\alpha_{1, j}+\alpha_{2} Z_{i, j}+\alpha_{3, j} X_{i}^{d}+\nu_{i, j}^{d}-P^{\prime}\left(Z_{i, j} ; \beta\right)=0
$$

However, in this case we are still able to easily find a closed-form solution for $\nu_{i, j}^{d}$ :

$$
\nu_{i, j}^{d}=P^{\prime}\left(Z_{i, j} ; \beta\right)-\alpha_{1, j}-\alpha_{2} Z_{i, j}-\alpha_{3, j} X_{i}^{d}
$$

Making the distributional assumption that $\nu_{i, j}^{d} \sim N\left(0, \sigma^{2}\right)$ and using a textbook application of a change of variables, it is straightforward to form the likelihood $\Pi_{i=1}^{N} \ell\left(Z_{i, j}, X_{i}^{d} ; \alpha, \sigma\right)$ where:

$$
\ell\left(Z_{i, j}, X_{i}^{d} ; \alpha, \sigma\right)=\frac{1}{\sigma \sqrt{2 \pi}} \exp \left\{-\frac{1}{2 \sigma^{2}}\left(\nu_{i, j}^{d}\right)^{2}\right\}\left|\frac{\partial \nu_{i, j}^{d}}{\partial Z_{i, j}}\right|
$$

To implement this Maximum Likelihood procedure, we only need to calculate the value of $\nu_{i, j}^{d}$ consistent with the observed value of $Z_{i, j}$ (given $\alpha, \widehat{\beta}$, and $X_{i}^{d}$ ) and the determinant of the Jacobian associated with the change of variables (i.e., we do not need to solve the differential equation for $Z_{i, j}$ ). Respectively, these terms are given by:

$$
\nu_{i, j}^{d}=P^{\prime}\left(Z_{i, j} ; \widehat{\beta}\right)-\alpha_{1, j}-\alpha_{2} Z_{i, j}-\alpha_{3, j} X_{i}^{d}
$$

and:

$$
\left|\frac{\partial \nu_{i, j}^{d}}{\partial Z_{i, j}}\right|=\left|P^{\prime \prime}\left(Z_{i, j} ; \widehat{\beta}\right)-\alpha_{2}\right|
$$

In practice, finding the vector of parameters that maximizes the likelihood is straight- 
forward and may even be reduced to a one-dimensional numerical optimization problem. ${ }^{12}$

The model presented thus far is one where $Z_{i, j}$ is a scalar amenity. However, our approach may be easily extended to estimate models that consider a $K$-dimensional vector of amenities denoted $\mathbf{Z}_{i, j}=\left[Z_{i, j}^{1}, \ldots, Z_{i, j}^{K}\right]$. Assuming that the elements of the vector $\boldsymbol{\nu}_{i, j}^{d}$ are distributed jointly normal with mean zero and variance-covariance matrix $\Sigma$, the likelihood may be formed employing the change-of-variables technique without the need to solve the differential equations for $\mathbf{Z}_{i, j}$. This likelihood is given by:

$$
\ell\left(\mathbf{Z}_{i, j}, X_{i}^{d}, \boldsymbol{\nu}_{i, j}^{d} ; \alpha, \boldsymbol{\Sigma}\right)=(2 \pi)^{-\frac{K}{2}}|\boldsymbol{\Sigma}|^{-\frac{1}{2}} \exp \left\{-\frac{\boldsymbol{\nu}_{i, j}^{d^{\prime} \Sigma^{-1}} \boldsymbol{\nu}_{i, j}^{d}}{2}\right\}\left|\frac{\partial\left(\nu_{i, j}^{d}, \ldots, \nu_{i, j}^{d} K\right.}{\partial\left(Z_{i, j}^{1}, \ldots, Z_{i, j}^{K}\right)}\right|
$$

where:

$$
\boldsymbol{\nu}_{i, j}^{d}=\left[\begin{array}{c}
\nu_{i, j}^{d 1} \\
\vdots \\
\nu_{i, j}^{d K}
\end{array}\right]=\left[\begin{array}{c}
\frac{\partial P\left(\mathbf{Z}_{i, j} ; \beta\right)}{\partial Z_{i, j}^{1}} \\
\vdots \\
\frac{\partial P\left(\mathbf{Z}_{i, j} ; \beta\right)}{\partial Z_{i, j}^{K}}
\end{array}\right]-\left[\begin{array}{c}
\alpha_{1, j}^{1} \\
\vdots \\
\alpha_{1, j}^{K}
\end{array}\right]-\left[\begin{array}{ccc}
\alpha_{2}^{1,1} & \cdots & \alpha_{2}^{1, K} \\
\vdots & \ddots & \vdots \\
\alpha_{2}^{K, 1} & \cdots & \alpha_{2}^{K, K}
\end{array}\right]\left[\begin{array}{c}
Z_{i, j}^{1} \\
\vdots \\
Z_{i, j}^{K}
\end{array}\right]-\left[\begin{array}{c}
\alpha_{3, j}^{1} \\
\vdots \\
\alpha_{3, j}^{K}
\end{array}\right] X_{i}^{d}
$$

Finally, while the MWTP function specified thus far has been both linear and additively separable in the idiosyncratic shock, $\nu_{i, j}^{d}$, richer specifications of the MWTP function may be estimated using our framework. Our estimator simply requires that one is able to isolate the idiosyncratic shock, $\nu_{i, j}^{d}$. For example, (returning to a scalar amenity, $Z$ ) if the MWTP function were given by: ${ }^{13}$

$$
P^{\prime}\left(Z_{i, j} ; \beta\right)=Z_{i, j}^{\alpha_{2}}\left(X_{i}^{d}\right)^{\alpha_{3, j}} \nu_{i, j}^{d}
$$

\footnotetext{
${ }^{12}$ Concentrating the likelihood function given by Equation (17) allows for a single-dimensional search over $\alpha_{2}$. For each iteration of the likelihood (i.e., for each guess of $\alpha_{2}$ ), the likelihood-maximizing values of $\alpha_{1, j}$ and $\alpha_{3, j}$ may be recovered through the least-squares regression of $\left(P^{\prime}\left(Z_{i, j} ; \widehat{\beta}\right)-\widehat{\alpha}_{2} Z_{i, j}\right)$ on market indicators and $X_{i}^{d}$, while the likelihood-maximizing value of $\sigma^{2}$ may be recovered as $\frac{1}{N} \sum_{i=1}^{N}\left(\nu_{i, j}^{d}\right)^{2}$.

${ }^{13}$ In this case, the underlying indirect utility function would be given by: $U\left(Z_{i, j}, X_{i}^{d} ; \alpha\right)=$ $\left(\frac{1}{\alpha_{2}+1}\right) Z_{i, j}^{\alpha_{2}+1}\left(X_{i}^{d}\right)^{\alpha_{3, j}} \nu_{i, j}^{d}+\left(I_{i}-P\left(Z_{i, j} ; \beta\right)\right)$.
} 
then $\nu_{i, j}^{d}$ may be recovered as:

$$
\nu_{i, j}^{d}=\frac{P^{\prime}\left(Z_{i, j} ; \widehat{\beta}\right)}{Z_{i, j}^{\alpha_{2}}\left(X_{i}^{d}\right)^{\alpha_{3, j}}}
$$

$\left|\frac{\partial \nu_{i, j}^{d}}{\partial Z_{i, j}}\right|$ may be recovered as:

$$
\left|\frac{\partial \nu_{i, j}^{d}}{\partial Z_{i, j}}\right|=\left|\frac{P^{\prime \prime}\left(Z_{i, j} ; \widehat{\beta}\right)-\alpha_{2} Z_{i, j}^{-1} P^{\prime}\left(Z_{i, j} ; \widehat{\beta}\right)}{Z_{i, j}^{\alpha_{2}}\left(X_{i}^{d}\right)^{\alpha_{3, j}}}\right|
$$

and the likelihood may be formed using the change-of-variables technique.

It is important to note that the contribution of this paper is to illustrate a new estimation approach that avoids the traditional endogeneity problems that have plagued the literature. As the formal identification of the hedonic model has been discussed in detail in Brown and Rosen (1982), Mendelsohn (1985), and particularly, Ekeland, Heckman, and Nesheim (2004) and Heckman, Matzkin, and Nesheim (2010), we instead provide an informal discussion of identification, as the nature of our estimator allows for easy illustration of what data features pin down the parameters of the MWTP function.

Consider the model with linear MWTP outlined earlier in this section. When the MWTP intercept $\left(\alpha_{1}\right)$, the coefficients on $X^{d}\left(\alpha_{3}\right)$, and the MWTP variance $\left(\sigma^{2}\right)$ are common across markets, they are identified by the mean $Z$, the covariance between $Z$ and $X^{d}$, and the variance of $Z$, respectively. Four sources of variation identify the slope of the MWTP function. The first source is the sensitivity of mean $Z$ to changes in the price gradient across markets. The second source is the sensitivity of the variance of $Z$ to changes in the price gradient across markets. The third source is the sensitivity of the covariance of $Z$ and $X$ to changes in the price gradient across markets. The final, fourth source is the nonlinearity of the price gradient; $Z$ will not be distributed normally when the gradient is nonlinear creating additional identifying variation (particularly if $Z$ is allowed to have market-specific distributions). 
When the intercept of the MWTP function is allowed to vary by market, the variation in mean $Z$ across markets is used to identify the market-specific intercepts of the MWTP function and is no longer available to identify the slope of MWTP. In this case, higher levels of mean $Z$ are associated with higher market-specific values for $\alpha_{1, j}$, all else equal. A similar logic applies when the coefficients on $X^{d}$ are allowed to vary by market and differences in

the covariance between $Z$ and $X^{d}$ are used to identify $\left\{\alpha_{3, j}\right\}_{j=1}^{J}$ or when the variance of $\nu^{d}$ is allowed to vary by market and variance of $Z$ is used to identify $\left\{\sigma_{j}^{2}\right\}_{j=1}^{J}$. Finally, when all of the parameters of the MWTP function are allowed to vary by market, this is analogous to multiple single-market cases and the non-linearity of the price gradient is the only remaining source of identification of the MWTP slope. This is consistent with the established wisdom in the hedonic literature - one either needs a non-linear hedonic price gradient or multi-market data to recover the full MWTP function.

\subsection{Monte Carlo Evidence}

In this subsection, we provide Monte Carlo evidence on the performance of our proposed estimator. We begin with Monte Carlo simulations of the simplest two-market model. From this starting point, we increase the number of markets and increase the level of heterogeneity in both the market-specific gradient intercepts and slopes. Finally, we allow the MWTP intercept to vary by market.

For the first simulations, the hedonic gradient is given by:

$$
P^{\prime}\left(Z_{i, j} ; \beta\right)=\beta_{1, j}+\beta_{2, j} Z_{i, j}
$$

and the first-order condition for utility maximization is given by:

$$
\alpha_{1}+\alpha_{2} Z_{i, j}+\nu_{i, j}^{d}-P^{\prime}\left(Z_{i, j} ; \beta\right)=0
$$


yielding the MWTP function:

$$
P^{\prime}\left(Z_{i, j} ; \beta\right)=\alpha_{1}+\alpha_{2} Z_{i, j}+\nu_{i, j}^{d}
$$

and optimal consumption of $Z$ :

$$
Z_{i, j}=\left(\frac{\alpha_{1}-\beta_{1, j}}{\beta_{2, j}-\alpha_{2}}\right)+\left(\frac{1}{\beta_{2, j}-\alpha_{2}}\right) \nu_{i, j}^{d}
$$

We allow the number of markets to take on the following values: $j=\{2,5,10,50\}$. We specify that $\beta_{1, j}=2+\eta_{1}$ and $\beta_{2, j}=0.7+\eta_{2}$ where $\eta_{1} \sim \gamma_{1} * U(-0.3,0.3)$ and $\eta_{2} \sim \gamma_{2} *$ $U(-0.15,0.15) . \gamma$ is allowed to take on the following values: $\gamma_{1}=\{1,2,3\}$ and $\gamma_{2}=\{0,1,2,3\}$.

In all cases, we keep the total number of observations fixed at $n=5,000$ with observations per market given by $\frac{n}{j}$. The number of Monte Carlo repetitions per experiment is 1,000 . We set the structural parameters to the following "true" values: $\alpha_{1}=3, \alpha_{2}=-0.3$, and $\sigma=0.5$.

The results in Table (1) show that there is very little bias in the finite samples, even in the case of only two markets with limited information coming from each market. The standard deviations of the estimated parameters are small relative to the parameters and, more importantly, the efficiency of the estimator is increasing in both market size and level of gradient heterogeneity.

For comparison, we run the same set of Monte Carlo experiments using the traditional two-step Rosen framework. Results are presented in Table (2). As expected, the estimator performs poorly, particularly when it comes to recovering the slope of the MWTP function, $\alpha_{2}$. In all cases (even with 50 markets and maximum gradient heterogeneity across markets), both the MWTP intercept $\left(\alpha_{1}\right)$ and the standard deviation of the preference shock $(\sigma)$ are significantly biased downwards. In addition, the MWTP slope is always biased upwards (as expected); in all but two of the experiments, the mean value of the slope takes on a positive 
Table 1: Bishop-Timmins Results (common $\alpha_{1}$ )

("true" parameter values: $\alpha_{1}=3, \alpha_{2}=-0.3, \sigma=0.5$ )

\begin{tabular}{|l|c|c|c|c|c|c|}
\hline & $\operatorname{mean}\left(\alpha_{1}\right)$ & $\operatorname{mean}\left(\alpha_{2}\right)$ & $\operatorname{mean}(\sigma)$ & $\operatorname{std}\left(\alpha_{1}\right)$ & $\operatorname{std}\left(\alpha_{2}\right)$ & $\operatorname{std}(\sigma)$ \\
\hline$j=2, \gamma_{1}=1, \gamma_{2}=0$ & 3.0035 & -0.3036 & 0.5015 & 0.0709 & 0.0706 & 0.0357 \\
$j=2, \gamma_{1}=2, \gamma_{2}=0$ & 3.0004 & -0.3006 & 0.5000 & 0.0354 & 0.0347 & 0.0182 \\
$j=2, \gamma_{1}=3, \gamma_{2}=0$ & 3.0000 & -0.3001 & 0.4998 & 0.0241 & 0.0231 & 0.0127 \\
$j=2, \gamma_{1}=\gamma_{2}=1$ & 3.0015 & -0.3016 & 0.5005 & 0.0460 & 0.0452 & 0.0233 \\
$j=2, \gamma_{1}=\gamma_{2}=2$ & 3.0002 & -0.3003 & 0.4999 & 0.0240 & 0.0222 & 0.0124 \\
$j=2, \gamma_{1}=\gamma_{2}=3$ & 3.0000 & -0.3001 & 0.4997 & 0.0171 & 0.0146 & 0.0091 \\
$j=5, \gamma_{1}=\gamma_{2}=1$ & 3.0002 & -0.3003 & 0.4999 & 0.0342 & 0.0331 & 0.0175 \\
$j=5, \gamma_{1}=\gamma_{2}=2$ & 2.9998 & -0.2999 & 0.4997 & 0.0182 & 0.0159 & 0.0097 \\
$j=5, \gamma_{1}=\gamma_{2}=3$ & 2.9998 & -0.2999 & 0.4997 & 0.0133 & 0.0100 & 0.0074 \\
$j=10, \gamma_{1}=\gamma_{2}=1$ & 3.0002 & -0.3003 & 0.4998 & 0.0309 & 0.0296 & 0.0158 \\
$j=10, \gamma_{1}=\gamma_{2}=2$ & 2.9998 & -0.2999 & 0.4997 & 0.0166 & 0.0141 & 0.0089 \\
$j=10, \gamma_{1}=\gamma_{2}=3$ & 2.9998 & -0.2999 & 0.4997 & 0.0123 & 0.0087 & 0.0069 \\
$j=50, \gamma_{1}=\gamma_{2}=1$ & 3.0000 & -0.3001 & 0.4998 & 0.0285 & 0.0271 & 0.0147 \\
$j=50, \gamma_{1}=\gamma_{2}=2$ & 2.9998 & -0.2999 & 0.4996 & 0.0155 & 0.0128 & 0.0084 \\
$j=50, \gamma_{1}=\gamma_{2}=3$ & 2.9998 & -0.2999 & 0.4996 & 0.0117 & 0.0078 & 0.0066 \\
\hline
\end{tabular}

value (implying an upward sloping demand curve).

Finally, we return to our estimator and run a set of experiments where the MWTP intercept, $\alpha_{1}$, is allowed to vary across markets. We specify that $\alpha_{1, j} \sim U(2,4)$, while keeping $\alpha_{2}=-0.3$ and $\sigma=0.5$. Note that in this specification, we require heterogeneity in the the slope of the gradients across markets and do not estimate the cases where $\gamma_{2}=0$. Our estimator performs well in each case, including the case with only two markets and minimum gradient heterogeneity. The results from these experiments are presented in Table (3). 
Table 2: Rosen Results (common $\alpha_{1}$ )

("true" parameter values: $\alpha_{1}=3, \alpha_{2}=-0.3, \sigma=0.5$ )

\begin{tabular}{|l|c|c|c|c|c|c|}
\hline & $\operatorname{mean}\left(\alpha_{1}\right)$ & $\operatorname{mean}\left(\alpha_{2}\right)$ & $\operatorname{mean}(\sigma)$ & $\operatorname{std}\left(\alpha_{1}\right)$ & $\operatorname{std}\left(\alpha_{2}\right)$ & $\operatorname{std}(\sigma)$ \\
\hline$j=2, \gamma_{1}=1, \gamma_{2}=0$ & 2.0385 & 0.6615 & 0.0980 & 0.0026 & 0.0026 & 0.0003 \\
$j=2, \gamma_{1}=2, \gamma_{2}=0$ & 2.1381 & 0.5619 & 0.1857 & 0.0044 & 0.0042 & 0.0009 \\
$j=2, \gamma_{1}=3, \gamma_{2}=0$ & 2.2649 & 0.4350 & 0.2572 & 0.0053 & 0.0049 & 0.0017 \\
$j=2, \gamma_{1}=\gamma_{2}=1$ & 2.0802 & 0.6129 & 0.1455 & 0.0035 & 0.0036 & 0.0007 \\
$j=2, \gamma_{1}=\gamma_{2}=2$ & 2.2557 & 0.4224 & 0.2598 & 0.0055 & 0.0049 & 0.0019 \\
$j=2, \gamma_{1}=\gamma_{2}=3$ & 2.4299 & 0.2332 & 0.3369 & 0.0068 & 0.0050 & 0.0029 \\
$j=5, \gamma_{1}=\gamma_{2}=1$ & 2.1492 & 0.5381 & 0.1984 & 0.0048 & 0.0047 & 0.0012 \\
$j=5, \gamma_{1}=\gamma_{2}=2$ & 2.4131 & 0.2525 & 0.3299 & 0.0068 & 0.0052 & 0.0028 \\
$j=5, \gamma_{1}=\gamma_{2}=3$ & 2.6150 & 0.0358 & 0.4022 & 0.0079 & 0.0047 & 0.0038 \\
$j=10, \gamma_{1}=\gamma_{2}=1$ & 2.1774 & 0.5076 & 0.2163 & 0.0050 & 0.0049 & 0.0014 \\
$j=10, \gamma_{1}=\gamma_{2}=2$ & 2.4654 & 0.1963 & 0.3501 & 0.0071 & 0.0051 & 0.0031 \\
$j=10, \gamma_{1}=\gamma_{2}=3$ & 2.6669 & -0.0187 & 0.4185 & 0.0081 & 0.0045 & 0.0040 \\
$j=50, \gamma_{1}=\gamma_{2}=1$ & 2.2022 & 0.4807 & 0.2309 & 0.0053 & 0.0050 & 0.0015 \\
$j=50, \gamma_{1}=\gamma_{2}=2$ & 2.5067 & 0.1519 & 0.3652 & 0.0073 & 0.0050 & 0.0033 \\
$j=50, \gamma_{1}=\gamma_{2}=3$ & 2.7046 & -0.0582 & 0.4299 & 0.0082 & 0.0043 & 0.0042 \\
\hline
\end{tabular}

Table 3: Bishop-Timmins Results (market-specific $\alpha_{1, j}$ )

("true" parameter values: $\alpha_{2}=-0.3, \sigma=0.5$ )

\begin{tabular}{|l|c|c|c|c|}
\hline & $\operatorname{mean}\left(\alpha_{2}\right)$ & $\operatorname{mean}(\sigma)$ & $\operatorname{std}\left(\alpha_{2}\right)$ & $\operatorname{std}(\sigma)$ \\
\hline$j=2, \gamma_{1}=\gamma_{2}=1$ & -0.3531 & 0.5263 & 0.2406 & 0.1209 \\
$j=2, \gamma_{1}=\gamma_{2}=2$ & -0.3139 & 0.5066 & 0.1028 & 0.0524 \\
$j=2, \gamma_{1}=\gamma_{2}=3$ & -0.3068 & 0.5031 & 0.0662 & 0.0345 \\
$j=5, \gamma_{1}=\gamma_{2}=1$ & -0.3277 & 0.5134 & 0.1535 & 0.0775 \\
$j=5, \gamma_{1}=\gamma_{2}=2$ & -0.3084 & 0.5037 & 0.0693 & 0.0359 \\
$j=5, \gamma_{1}=\gamma_{2}=3$ & -0.3045 & 0.5018 & 0.0431 & 0.0233 \\
$j=10, \gamma_{1}=\gamma_{2}=1$ & -0.3221 & 0.5103 & 0.1335 & 0.0675 \\
$j=10, \gamma_{1}=\gamma_{2}=2$ & -0.3068 & 0.5027 & 0.0606 & 0.0316 \\
$j=10, \gamma_{1}=\gamma_{2}=3$ & -0.3036 & 0.5012 & 0.0370 & 0.0204 \\
$j=50, \gamma_{1}=\gamma_{2}=1$ & -0.3193 & 0.5069 & 0.1220 & 0.0616 \\
$j=50, \gamma_{1}=\gamma_{2}=2$ & -0.3061 & 0.5003 & 0.0554 & 0.0290 \\
$j=50, \gamma_{1}=\gamma_{2}=3$ & -0.3033 & 0.4990 & 0.0333 & 0.0186 \\
\hline
\end{tabular}




\section{Data}

We apply our estimator to valuing the willingness to pay to avoid violent crime in the San Francisco Metropolitan Area over the period 1994 to 2000. Further details and results of this application are discussed in Sections 5 and 6 .

In the first stage of our estimation, we recover the parameters of the hedonic price function for each year of our sample. In the second stage of our estimation, we recover the structural parameters of the linear MWTP function, allowing MWTP to vary with demographic characteristics. Finally, to demonstrate the policy implications of various hedonic estimators, we consider the non-marginal policy analysis of the observed changes in crime for the one year period of 1999 to 2000.

To estimate these specifications, we employ a varied set of data from multiple sources. These data and our sample cuts are discussed below.

\subsection{Property Transactions Data}

The real estate transactions data that we employ covers six counties of the San Francisco Bay Area (Alameda, Contra Costa, Marin, San Francisco, San Mateo, and Santa Clara) over the period 1994 to 2000. This dataset (used under a licensing agreement with DataQuick, Inc.) includes dates, prices, loan amounts, and buyers', sellers', and lenders' names for all transactions. In addition, for the final observed transaction of each single-family property, the dataset includes housing characteristics such as exact street address, square footage, year built, lot size, number of bedrooms, and number of bathrooms.

Additional data cuts are made in order to deal with the fact that DataQuick only reports

housing characteristics at the time of the final observed transaction, but we need to use housing 
characteristics from all transactions as controls in our hedonic price regressions. ${ }^{14}$ First, to control for land sales or total re-builds, we drop all transactions where "year built" is missing or later than the observed transaction date. Second, to control for major improvements or degradations, we drop any property with an observed average appreciation or depreciation rate exceeding the county- and year- specific mean price change by more than 50 percentage points (in either direction). Additionally, we drop any property that moves more than 40 percentile points (in either direction) between transactions in the overall county- and yearspecific distribution of price. We drop transactions where the price is missing or zero and, after using the consumer price index to convert all transaction prices into 2000 dollars, we drop one percent of observations from each tail of the price distribution to minimize the effect of outliers. As we merge the pollution data using the property's geographic coordinates, we drop properties where latitude and longitude are missing. Finally, we drop houses with more than three observed transactions over the 7 year sample and drop multiple sales within a given year. ${ }^{15}$

This yields a final sample of 403,036 transactions. Table (4) reports the summary statistics for the property transactions data.

\subsection{Household Demographic Data}

For our demographic characteristics, we use information on the race and income of buyers recorded on mortgage applications and published in accordance with the Home Mortgage Disclosure Act (HMDA) of 1975. The HMDA data also describe the mortgage lender's name, the loan amount, the year, and the property's census tract. As the variables of lender name,

\footnotetext{
${ }^{14}$ Approximately fifty-five percent of observed sales are the only observed sale for the property.

${ }^{15}$ To maintain a fairly homogenous sample (i.e., properties that would be competing in the same housing market), we make the additional sample cuts. We drop houses where "year built" is less than 1850, "lot size" is greater than 3 acres, "square footage" is zero or greater than 10,000 square feet, total "number of bathrooms" is greater than 10, total "number of bedrooms" is greater than 10, total "number of rooms" is missing or greater than 15 , and "number of stories" is missing or greater than 3.
} 
Table 4: Property Transactions Summary Statistics

\begin{tabular}{|l|c|c|}
\hline Variable & Mean & Std. Dev. \\
\hline Price (constant 2000 dollars) & $345,823.00$ & $192,210.00$ \\
Year Built & 1966.64 & 23.16 \\
Lot Size (sq. ft) & $6,453.55$ & $7,927.96$ \\
Square Footage & 1662.76 & 671.69 \\
Number Bathrooms & 2.07 & 0.73 \\
Number Bedrooms & 3.01 & 1.09 \\
Property Crimes (per 100,000 residents) & $1,803.43$ & 771.48 \\
Violent Crimes (per 100,000 residents) & 445.69 & 241.19 \\
\hline
\end{tabular}

loan amount, year, and census tract are also available in the DataQuick data, we are able to merge the buyer characteristics data with the property transactions data using the algorithm described in Bayer et. al. (2011). ${ }^{16}$ We drop all households where either race or income is missing.

Table (5) reports the summary statistics for the sample of buyers in both the full sample and in the restricted, 1999-only sample. This restricted sample will be used in the policy analysis that demonstrates the implications of valuing non-marginal changes in violent crime rates.

\subsection{Violent Crime Data}

The violent crime rate that we employ comes from the RAND California database and is defined as the number of incidents per 100,000 residents. ${ }^{17}$ Violent crime is reported for each

\footnotetext{
${ }^{16}$ Using this algorithm, we are able to uniquely match approximately eighty percent of all housing transactions to buyers in the HMDA dataset. The characteristics of the final sample of buyers and houses is remarkably close to those found in IPUMS samples. See Bayer et. al. (2011) for examples and further discussion.

${ }^{17}$ In the data, violent crime is defined as "crimes against people, including homicide, forcible rape, robbery, and aggravated assault."
} 
Table 5: Buyer Summary Statistics (Full- and 1999- Samples)

\begin{tabular}{|l|c|c|c|c|}
\hline \multirow{2}{*}{} & \multicolumn{2}{|c|}{$\begin{array}{c}\text { Full Sample } \\
(n=262,498)\end{array}$} & \multicolumn{2}{c|}{$\begin{array}{c}\text { 1999 Sample } \\
(n=49,438)\end{array}$} \\
\hline Variable & Mean & Std. Dev. & Mean & Std. Dev. \\
\hline Price & $354,002.90$ & $193,464.20$ & $372,028.60$ & $200,698.10$ \\
Violent Crime & 445.46 & 242.24 & 369.06 & 171.67 \\
Income & $111,312.90$ & $111,607.30$ & $111,338.40$ & $87,321.00$ \\
White & 0.63 & 0.48 & 0.61 & 0.49 \\
Asian & 0.24 & 0.42 & 0.25 & 0.43 \\
Black & 0.04 & 0.19 & 0.03 & 0.18 \\
Hispanic & 0.10 & 0.30 & 0.11 & 0.31 \\
\hline
\end{tabular}

Prices and incomes are expressed in constant 2000 dollars. The violent crime rate is per 100,000 residents.

of the 80 cities in the San Francisco Metropolitan Area for each year of our data. Figure (1) illustrates the locations of these cities.

Figure 1: Locations of Crime-reporting Cities within the San Francisco Metro Area

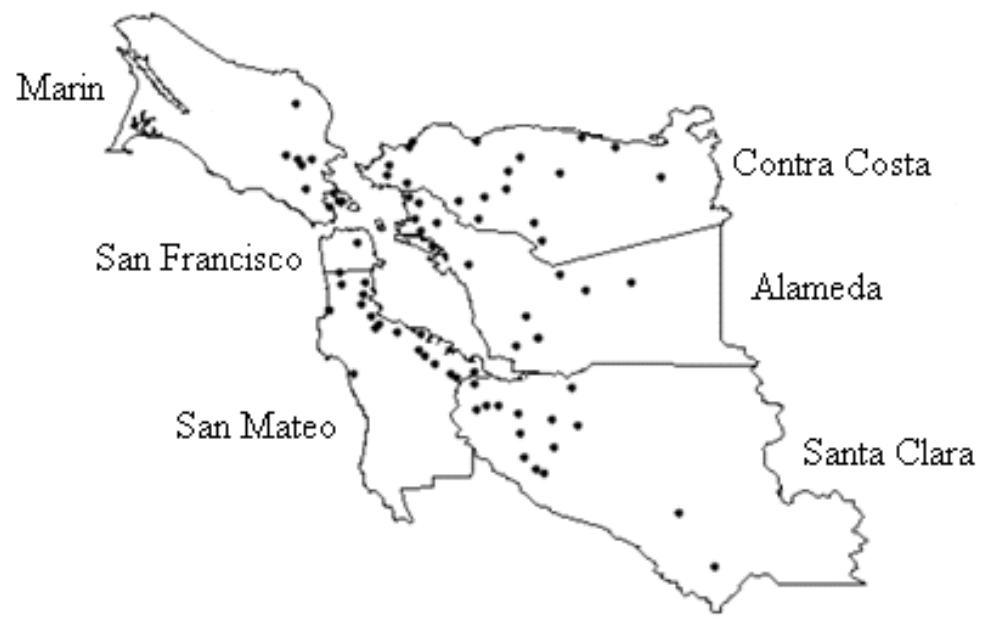

For our analysis, we impute a violent crime rate for each individual house using an 
inverse distance-squared weighted average of the crime rate in each city. ${ }^{18}$ As a control in our hedonic regressions, we also create an analogous measure of property crime rates from the RAND California database. ${ }^{19,20}$ Table (4) provides summary statistics for both violent crime and property crime at the level of the house. Table (5) provides summary statistics for our variable of interest, violent crime, at the level of the buyer.

We see a significant amount of variation (both cross-sectional and time-series) in our key variable of interest, violent crime. Figures (2) and (3) illustrate the distribution of violent crime rates and the time-trend of mean violent crime rates, respectively. The declining trend observed in the San Francisco Metropolitan Area is consistent with the decreases in violent crime observed in most of the US over the same period.

Figure 2: Distribution of Violent Crime Rates (Incidents per 100,000 Residents)

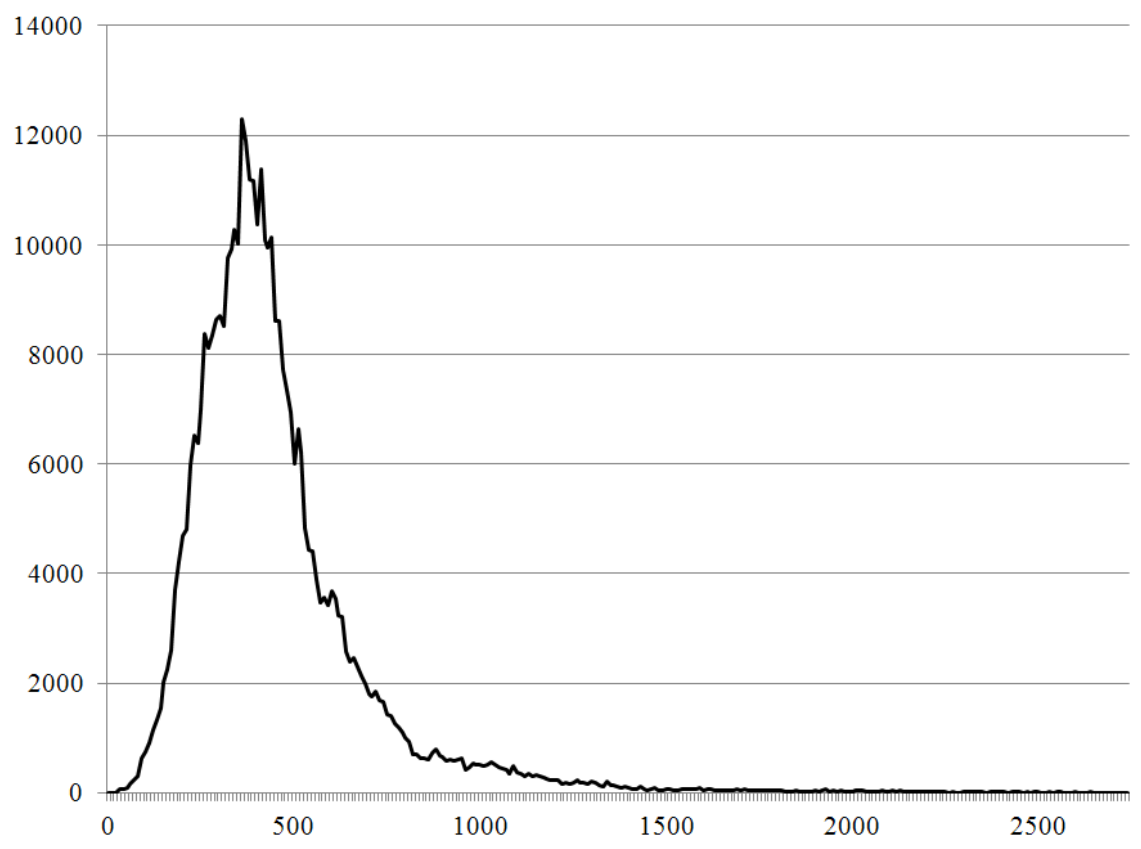

\footnotetext{
${ }^{18}$ Distance is computed using the Great Circle estimator, geographic coordinates of city centroids, and geographic coordinates of each house.

${ }^{19}$ Property crime is defined as "crimes against property, including burglary and motor vehicle theft."

${ }^{20} \mathrm{We}$ use the property crime rate as a control in our hedonic estimation and focus attention on violent crimes in our valuation exercise, as violent crimes are less likely to be subject to systematic under-reporting (Gibbons (2004)).
} 
Figure 3: Time Variation in Violent Crime Rates (Incidents per 100,000 Residents)

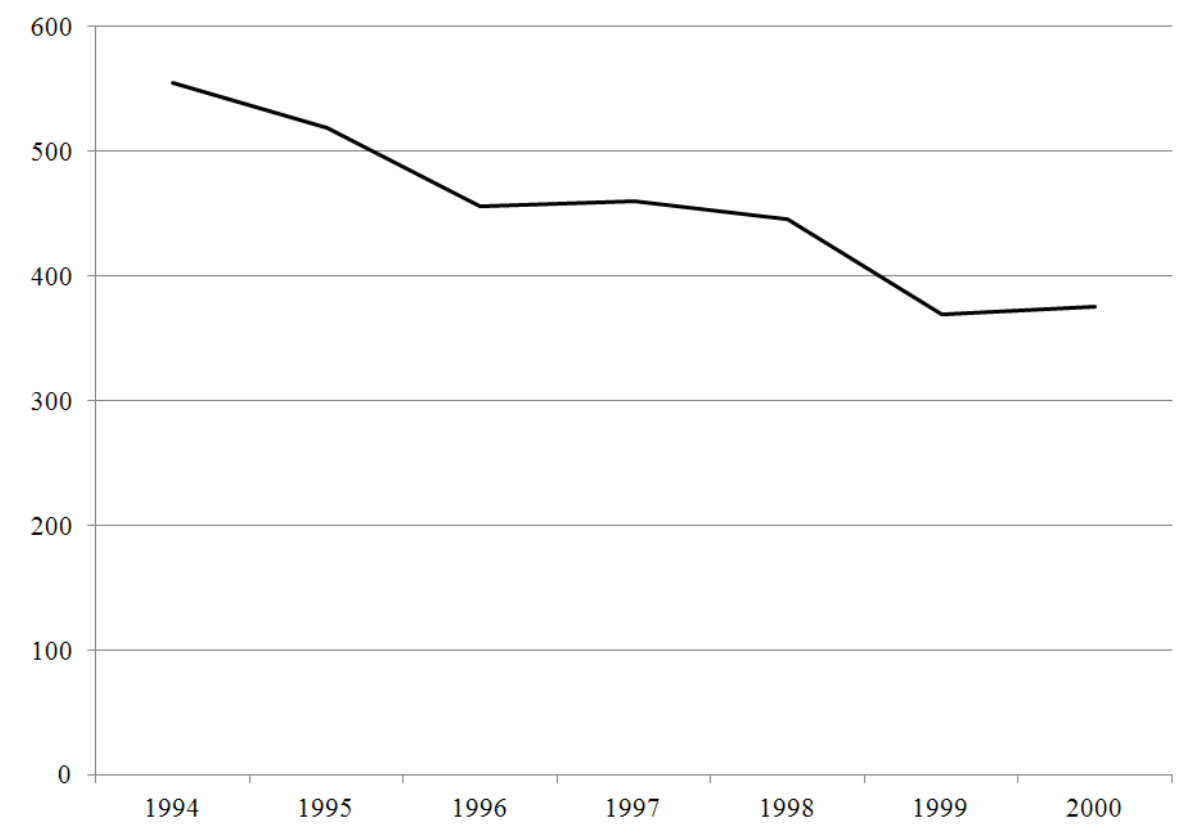

\section{Results}

\subsection{Hedonic Price Function}

In this subsection, we discuss the results from the estimation of a log-linear hedonic price function. Separately for each year, 1994 to 2000, we regress the log of sales price on housing attributes and tract-level fixed effects. Regression results are reported in Table (6), with each row representing a separate annual regression. In the vast majority of cases, hedonic price estimates have the expected sign and magnitude. ${ }^{21}$

For discussion purposes, we calculate the implicit price of each attribute at the mean housing price of $\$ 345,823$, given in 2000 dollars, and annualize these implicit prices by multi-

\footnotetext{
${ }^{21}$ An exception is the sign on property crime, which exhibits a counterintuitive positive sign in 1994 and 1996. This is not surprising as property crime is usually considered to be under-reported (unlike violent crime, which we focus on in our analysis). If underreporting is more severe in low-price neighborhoods, this could the coefficient to be biased upwards.
} 
Table 6: Hedonic Price Function Estimates

\begin{tabular}{|c|c|c|c|c|c|c|c|}
\hline & Year Built & Lot Size & Sq. Footage & Bathrooms & Bedrooms & Prop. Crime & Violent Crime \\
\hline 1994 & $8.26 \mathrm{E}-04^{* * *}$ & $6.47061 \mathrm{E}-06^{* * *}$ & $3.45 \mathrm{E}-04^{* * *}$ & $6.00 \mathrm{E}-03^{* *}$ & $0.0348^{* * *}$ & $-4.77 \mathrm{E}-05^{* * *}$ & $-2.65 \mathrm{E}-04^{* * *}$ \\
& $(9.36 \mathrm{E}-05)$ & $(2.57963 \mathrm{E}-07)$ & $(3.24 \mathrm{E}-06)$ & $(2.77 \mathrm{E}-03)$ & $(1.69 \mathrm{E}-03)$ & $(5.81 \mathrm{E}-06)$ & $(2.40 \mathrm{E}-05)$ \\
1995 & $8.19 \mathrm{E}-04^{* * *}$ & $6.63532 \mathrm{E}-06^{* * *}$ & $3.49 \mathrm{E}-04^{* * *}$ & $9.51 \mathrm{E}-03^{* * *}$ & $0.0370^{* * *}$ & $-1.04 \mathrm{E}-05$ & $-5.04 \mathrm{E}-04^{* * *}$ \\
& $(1.09 \mathrm{E}-04)$ & $(2.95071 \mathrm{E}-07)$ & $(4.76 \mathrm{E}-06)$ & $(3.53 \mathrm{E}-03)$ & $(1.93 \mathrm{E}-03)$ & $(6.92 \mathrm{E}-06)$ & $(3.30 \mathrm{E}-05)$ \\
1996 & $7.41 \mathrm{E}-04^{* * *}$ & $6.53443 \mathrm{E}-06^{* * *}$ & $3.58 \mathrm{E}-04^{* * *}$ & $0.0136^{* * *}$ & $0.0432^{* * *}$ & $-1.64 \mathrm{E}-05^{* *}$ & $-4.64 \mathrm{E}-04^{* * *}$ \\
& $(8.85 \mathrm{E}-05)$ & $(3.3423 \mathrm{E}-07)$ & $(4.29 \mathrm{E}-06)$ & $(3.24 \mathrm{E}-03)$ & $(1.69 \mathrm{E}-03)$ & $(7.50 \mathrm{E}-06)$ & $(3.05 \mathrm{E}-05)$ \\
1997 & $4.40 \mathrm{E}-04^{* * *}$ & $7.12735 \mathrm{E}-06^{* * *}$ & $3.57 \mathrm{E}-04^{* * *}$ & $0.0186^{* * *}$ & $0.0430^{* * *}$ & $8.05 \mathrm{E}-07$ & $-6.04 \mathrm{E}-04^{* * *}$ \\
1998 & $(7.61 \mathrm{E}-05)$ & $(2.64862 \mathrm{E}-07)$ & $(4.62 \mathrm{E}-06)$ & $(3.03 \mathrm{E}-03)$ & $(1.67 \mathrm{E}-03)$ & $(8.48 \mathrm{E}-06)$ & $(2.95 \mathrm{E}-05)$ \\
1999 & $2.34 \mathrm{E}-04^{* * *}$ & $7.05921 \mathrm{E}-06^{* * *}$ & $3.56 \mathrm{E}-04^{* * *}$ & $0.0251^{* * *}$ & $0.0430^{* * *}$ & $1.13 \mathrm{E}-04^{* * *}$ & $-9.73 \mathrm{E}-04^{* * *}$ \\
& $(8.55 \mathrm{E}-05)$ & $(3.33583 \mathrm{E}-07)$ & $(6.01 \mathrm{E}-06)$ & $(3.59 \mathrm{E}-03)$ & $(2.03 \mathrm{E}-03)$ & $(9.16 \mathrm{E}-06)$ & $(3.98 \mathrm{E}-05)$ \\
2000 & $9.28 \mathrm{E}-05$ & $7.38838 \mathrm{E}-06^{* * *}$ & $3.55 \mathrm{E}-04^{* * *}$ & $0.0211^{* * *}$ & $0.0451^{* * *}$ & $6.18 \mathrm{E}-05^{* * *}$ & $-1.01 \mathrm{E}-03^{* * *}$ \\
& $(7.99 \mathrm{E}-05)$ & $(2.52938 \mathrm{E}-07)$ & $(3.30 \mathrm{E}-06)$ & $(2.51 \mathrm{E}-03)$ & $(1.37 \mathrm{E}-03)$ & $(9.68 \mathrm{E}-06)$ & $(3.35 \mathrm{E}-05)$ \\
& $3.86 \mathrm{E}-04^{* * *}$ & $8.016 \mathrm{E}-06^{* * *}$ & $3.35 \mathrm{E}-04^{* * *}$ & $0.0246^{* * *}$ & $0.0431^{* * *}$ & $1.32 \mathrm{E}-04^{* * *}$ & $-1.22 \mathrm{E}-03^{* * *}$ \\
& $(8.55 \mathrm{E}-05)$ & $(3.6165 \mathrm{E}-07)$ & $(4.24 \mathrm{E}-06)$ & $(2.97 \mathrm{E}-03)$ & $(1.71 \mathrm{E}-03)$ & $(1.03 \mathrm{E}-05)$ & $(4.74 \mathrm{E}-05)$ \\
\hline
\end{tabular}

Dependent variable is the log of sales price. Data are mean-differenced to remove 830 tract-level fixed effects. Significance is indicated by: ${ }^{* *}(0.01),{ }^{* *}(0.05)$, and $*(0.10)$.

plying them by $0.05 .^{22}$ The implicit price of an additional square foot of lot size is, on average, 11 cents per year in 1994. The implicit price of an additional square foot of living space is $\$ 5.97$ per year in 1994 . These prices vary somewhat, but are relatively stable over time. Also in 1994 , an additional bathroom costs $\$ 103.75$ per year, while an additional bedroom costs $\$ 602.37$ per year. The implicit prices of bedrooms and bathrooms vary somewhat over time, while the effect of year built varies a great deal over time (both in magnitude and sign).

Our amenity of interest, violent crime, exhibits an intuitive negative effect on housing prices that is statistically significant. Over the period of our sample, we see this effect increasing over time. In 1994, the implicit price of additional unit of violent crime is $-\$ 4.59$, while in 2000 it is $-\$ 21.07$. Table (7) reports the year-to-year variation in the implicit price

\footnotetext{
${ }^{22}$ These measures of implicit price are those that often used as simple, marginal measures of willingness to pay in the existing literature.
} 
of violent crime.

Table 7: Variation in the Implicit Price of Violent Crime

\begin{tabular}{|c|c|}
\hline Year & Implicit Price \\
\hline 1994 & -4.59 \\
1995 & -8.71 \\
1996 & -8.02 \\
1997 & -10.44 \\
1998 & -16.82 \\
1999 & -17.48 \\
2000 & -21.07 \\
\hline
\end{tabular}

\subsection{MWTP Function}

In this subsection, we report the results from our procedure for recovering estimates of the MWTP function using the first-stage hedonic price function estimates and data on individual home buyers. With the log-linear specification for the hedonic price function, a closed-form solution for $Z_{i, j}$ cannot be recovered and we employ a change of variables from $Z$ to $\nu^{d}$. We specify a linear MWTP function and allow the intercept of the MWTP function to vary by year by including a set of year dummies in our estimation:

$$
P^{\prime}\left(V C_{i, t} ; \beta\right)=\alpha_{1, t}+\alpha_{2} V C_{i, t}+X_{i}^{d^{\prime}} \alpha_{3}+\nu_{i, t}^{d}
$$

where:

$$
\nu_{i, t}^{d} \sim N\left(0, \sigma^{2}\right)
$$

and $X_{i}^{d}$ is a vector comprised of income (in thousands of 2000 dollars) and a vector of race dummies (Asian-Pacific Islander, black, Hispanic, and white). ${ }^{23}$

\footnotetext{
${ }^{23}$ White is the excluded race.
} 
The first column of Table (8) reports the results from our estimator. First, consider the coefficient on violent crime, $\alpha_{2}$, which reveals the amount by which the individual's MWTP to avoid violent crime changes with an increase in this disamenity. Intuitively, this coefficient should be negative, indicating that the MWTP to avoid violent crime increases as the rate of violent crime increases (consistent with a demand curve for public safety that is downward sloping). We find this to be the case with our model; each additional incident per 100,000 residents raises MWTP to avoid violent crime by 10 cents. As we show in Section 6, this has important implications for the value ascribed to large reductions in violent crime rates like those witnessed over the period of our sample.

Looking at the the remaining coefficient estimates derived using our model, an increase in income of $\$ 1,000$ per year increases MWTP to avoid violent crime by 5.8 cents (consistent with public safety being a normal good). Considering differences in MWTP by race, the excluded group (Whites) has the highest mean MWTP to avoid violent crime. Our model suggests that Asian-Pacific Islanders have a slightly lower mean MWTP (as indicated by their positive intercept shift of $\$ 2.84$ ). Blacks have the lowest mean MWTP to avoid violent crime, followed by Hispanics.

For the sake of comparison, the second column of Table (8) reports the results from the traditional Rosen estimation approach. These results are strikingly different from the results presented in the first column. In contrast to our estimator, estimates from the Rosen model suggest that increases in violent crime reduce the MWTP to avoid violent crime (indicating that the demand curve for public safety is upward sloping). This is exactly the direction of bias suggested by both Bartik and Epple and leads to upwardly biased estimates of the welfare associated with non-marginal reductions in violent crime (which we show in Section 6). Additionally, while the coefficient on income is of the same sign, the magnitude is much smaller. Finally, race does not appear to play an economically significant role in the estimates derived using the Rosen estimation approach (although the coefficients are statistically significant). 
Table 8: MWTP Function Estimates

\begin{tabular}{|c|c|c|}
\hline & Bishop-Timmins & Rosen \\
\hline Violent Crime & $\begin{array}{c}-0.1008 \\
(3.66 \mathrm{E}-03)\end{array}$ & $\begin{array}{c}3.51 \mathrm{E}-03 \\
(1.05 \mathrm{E}-04)\end{array}$ \\
\hline Income $(/ 1000)$ & $\begin{array}{c}-0.0581 \\
(4.88 \mathrm{E}-03)\end{array}$ & $\begin{array}{c}-0.0252 \\
(2.75 \mathrm{E}-03)\end{array}$ \\
\hline Asian & $\begin{array}{c}2.8352 \\
(0.1868)\end{array}$ & $\begin{array}{c}0.0949 \\
(0.0337)\end{array}$ \\
\hline Black & $\begin{array}{l}25.0498 \\
(0.9251)\end{array}$ & $\begin{array}{c}1.9942 \\
(0.0684)\end{array}$ \\
\hline Hispanic & $\begin{array}{l}13.9813 \\
(0.5706)\end{array}$ & $\begin{array}{c}1.1989 \\
(0.0748)\end{array}$ \\
\hline Constant & $\begin{array}{l}54.1218 \\
(1.6280)\end{array}$ & $\begin{array}{l}-3.3790 \\
(0.3542)\end{array}$ \\
\hline 1995 dummy & $\begin{array}{c}-6.2501 \\
0.5187\end{array}$ & $\begin{array}{c}-2.2899 \\
0.4489\end{array}$ \\
\hline 1996 dummy & $\begin{array}{c}-11.8685 \\
0.5090\end{array}$ & $\begin{array}{c}-1.5536 \\
0.4167\end{array}$ \\
\hline 1997 dummy & $\begin{array}{c}-12.8032 \\
0.5172\end{array}$ & $\begin{array}{l}-3.1074 \\
0.3957\end{array}$ \\
\hline 1998 dummy & $\begin{array}{c}-18.4337 \\
0.6021\end{array}$ & $\begin{array}{c}-7.2178 \\
0.4639\end{array}$ \\
\hline 1999 dummy & $\begin{array}{c}-27.1906 \\
0.7219\end{array}$ & $\begin{array}{c}-7.5220 \\
0.4835\end{array}$ \\
\hline 2000 dummy & $\begin{array}{c}-29.8092 \\
0.8100\end{array}$ & $\begin{array}{c}-10.7238 \\
0.6091\end{array}$ \\
\hline$\sigma_{\nu}$ & $\begin{array}{c}23.8670 \\
0.8092\end{array}$ & $\begin{array}{l}- \\
-\end{array}$ \\
\hline
\end{tabular}

All coefficients are significant at the $1 \%$ level of significance.

\section{Measuring the Welfare Implications of a Non-Marginal Change in Violent Crime Rates}

As is clear from our data description, the San Francisco Metropolitan Area experienced a large and persistent reduction in average violent crime rates over the course of our sample 
period. Similar reductions have been observed in numerous other cities across the US. Out of the 25 cities that he considers, Levitt (2004) ranks San Francisco 12th in terms of the size of the reduction in homicides experienced between 1991 - 2001. This change in the violent crime rate represents a significant improvement on average and is, importantly, non-marginal. ${ }^{24}$

There is a large and growing literature aimed at valuing the benefits of crime reductions (with, for example, the goal of conducting cost-benefit analysis of police force expansions). This literature was recently surveyed by Heaton (2010). He notes that the property value hedonic technique is valuable for recovering the intangible costs of crime (e.g., lost quality of life for fear of victimization or effective loss of public space). Such intangibles are likely to be particularly important for measuring the costs of violent crime (a point emphasized by Linden and Rockoff (2008) with respect to sexual offenses).

For this welfare analysis, we consider the set of all individuals who purchased a house in 1999 (summary statistics describing these individuals is given in Table (5)). We then measure the value of the crime changes that these individuals actually experienced between 1999 and 2000. It is highly likely that these individuals still occupy the same residence in 2000 and, as we show in this section, the changes that occurred over this year were substantial enough that proper identification of the MWTP function becomes important in measuring their change in welfare. In particular, Figure (4) illustrates the distribution of changes in violent crime rates experienced by this set of households. The 1999 data allows us to consider the welfare changes associated with both reductions and increases in crime; approximately sixty percent of these households experienced reductions in violent crime during this period while the remaining forty percent experienced increases in violent crime.

\footnotetext{
${ }^{24}$ Levitt (2004) discusses six factors that he argues were not responsible for these declines, including economic growth and reduced unemployment, shifting age and racial demographics, changes in policing strategies, changes in gun control laws and laws controlling concealed weapons, and changes in capital punishment. He argues instead that there is a strong case to be made for the role of increasing size of the police force, increased incarceration rats, declines in the crack epidemic, and the legalization of abortion twenty years prior. The relative importance of each of these factors is still a contentious topic. See, for example, Blumstein and Wallman (2006).
} 
Figure 4: Distribution of One-Year Violent Crime Rate Changes for 1999 Buyers

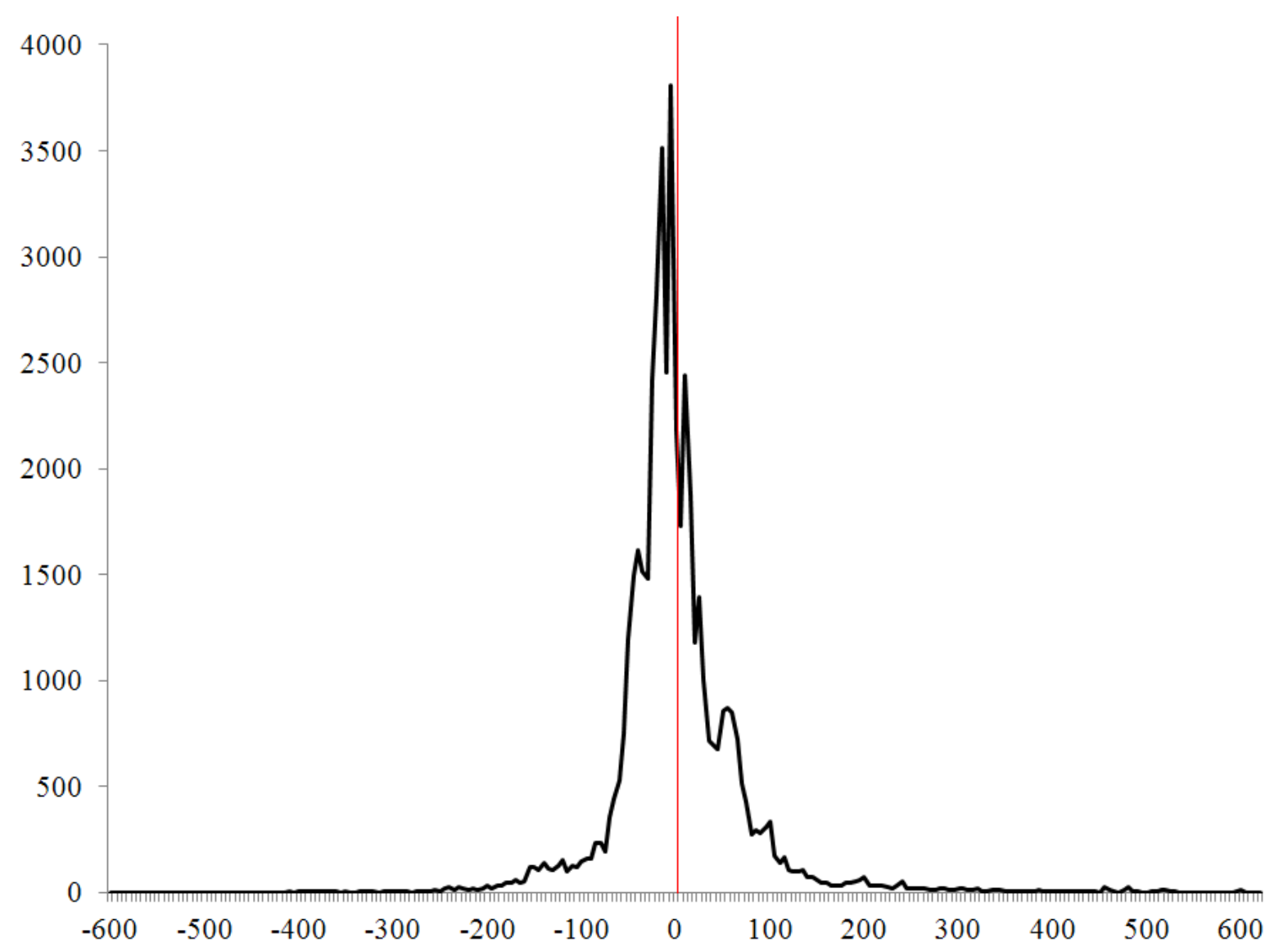

For the purposes of illustration, we report valuations based on three different estimation strategies: (i) Bishop-Timmins, (ii) Rosen, and (iii) horizontal MWTP. The third approach assigns a constant willingness to pay to each individual equal to the slope of the hedonic price function at their observed housing choice. As the utility function is assumed to be linear in $Z$ (i.e., the MWTP function is constant in $Z$ ), this approach corresponds to either the "inversion" procedure outlined in Bajari and Benkard (2005) or to the Rosen (1974) model where the endogeneity problem is trivially solved by assuming that the MWTP function doesn't depend on $Z$. In this case, the welfare effects may be calculated as the area of the rectangle under the horizontal MWTP, with the width given by the experienced change in violent crime. For the first two strategies, the value associated with a change in the violent 
crime rate is calculated as the area of the trapezoid under the MWTP function over the width of the experienced change in violent crime.

We report results separately for the sixty percent of buyers who experienced a reduction in their violent crime rate and for the remaining forty percent of buyers who experienced an increase in Table (9). ${ }^{25}$ Note that the large standard deviations of WTP illustrate skewness of the distributions, versus individuals experiencing counterintuitive (positive) signs on their WTP.

Table 9: WTP for Non-Marginal Changes in Violent Crime

\begin{tabular}{|l|c|c|c|c|}
\hline & $\begin{array}{c}\text { Buyers with Reductions } \\
(n=29,953)\end{array}$ & $\begin{array}{c}\text { Buyers with Increases } \\
(n=19,485)\end{array}$ \\
\hline & $\begin{array}{c}\text { Average } \\
\text { WTP }\end{array}$ & $\begin{array}{c}\text { Std. Dev. } \\
\text { WTP }\end{array}$ & $\begin{array}{c}\text { Average } \\
\text { WTP }\end{array}$ & $\begin{array}{c}\text { Std. Dev. } \\
\text { WTP }\end{array}$ \\
\hline Bishop-Timmins & 269.57 & 328.26 & -980.69 & 1896.06 \\
Rosen & 401.15 & 543.86 & -581.88 & 679.76 \\
Horizontal MWTP & 395.83 & 532.83 & -595.31 & 710.78 \\
\hline
\end{tabular}

The bias from improperly accounting for the effect of a non-marginal change in violent crime on MWTP is evident. Consider first the case of crime reductions. The Rosen model and horizontal MWTP yield estimates of the average WTP for observed reductions that are 1.49 times greater than our model, implying an almost fifty-percent upward bias. The direction of the bias is reversed when we consider increases in the rates of violent crime. Here, the alternative models yield estimates of average WTP for observed crime reductions that are only 0.59 of our estimate. These differences are far from trivial and would have an important impacts on any cost-benefit analysis.

\footnotetext{
${ }^{25}$ In the calculations for buyers experiencing a decrease in violent crime, we restrict the marginal willingness to pay curve to be non-positive. This has little effect on the welfare implications; our average willingness to pay without this restriction is 243.68 .
} 


\section{Conclusion}

Researchers regularly ascribe downward sloping demand curves to households for goods ranging from breakfast cereals to BMWs. In fact, recovering the price elasticity of demand for such goods constitutes one of the main activities undertaken by applied microeconomists. However, because of the difficult endogeneity problems associated with the recovery of the MWTP function using the hedonic technique, the same flexibility has generally not been applied to household demand for local public goods and amenities. Instead, applications of the hedonic method have tended to focus only on the first-stage hedonic price regression; recovering parameters that only yield valid welfare estimates for marginal policies. In order to properly evaluate the welfare effects associated with larger policies, the researcher must recover the structural parameters of the MWTP function. In this paper, we propose an estimation approach for the recovery of these parameters, while avoiding the endogeneity problems so commonly associated with the hedonic model.

We show that there is no fundamental endogeneity problem in the hedonic model; the endogeneity problems are largely manufactured and are a result of framing Rosen's second stage regression in terms of marginal cost (implicit attribute price) equaling marginal benefit (marginal utility from consuming the amenity in question). We instead rearrange the information provided by the hedonic equilibrium and arrive at a simple modeling environment with a single endogenous outcome variable, a vector of exogenous variables, and an econometric error.

Estimation of the model is straightforward and consists of a standard Maximum Likelihood procedure which employs a textbook change-of-variables technique. In a restricted version of the model, a closed-form solution for the amenity of interest may be found analytically and the change of variables is not required. Estimation in the simplest version of the model may even be reduced to an indirect least squares procedure, exploiting the one-to-one 
mapping between the structural and reduced-form parameters. Like the Rosen model, our approach is (i) quite intuitive, as it is derived from the first-order condition for utility maximization, (ii) able to incorporate rich individual- and market- level heterogeneity, and (iii) computationally light and easy to implement. Additionally, our model requires no more in terms of data than the standard hedonic model.

Using a series of Monte Carlo experiments, we demonstrate that our proposed estimator presents very little bias in finite samples. Applying our model to data on violent crime rates in California's Bay Area, we find that properly accounting for the shape of the MWTP function has important implications for measuring the welfare effects of non-marginal changes in violent crime. Considering the welfare effects associated with the observed one-year change in crime for those households that purchased a house in 1999, we find that alternative modeling procedures overstate benefits (for those households which experienced a decrease in violent crime) by fifty percent relative to our approach and understate costs (for those households which experienced an increase in violent crime) by forty percent relative to our approach. These differences are both statistically and economically significant and consequential for cost-benefit analyses of policies that may have large impacts on future crime rates. 


\section{References}

Bajari, P., and C.L. Benkard. 2005. "Demand Estimation with Heterogeneous Consumers and Unobserved Product Characteristics: A Hedonic Approach." Journal of Political Economy, 113(6): 1239-1276.

Bajari, P., J. Cooley, K. Kim, and C. Timmins. 2010. "A Theory-Based Approach to Hedonic Price Regressions with Time-Varying Unobserved Product Attributes: The Price of Pollution." American Economic Review, forthcoming.

Bartik, T.J. 1987. "The Estimation of Demand Parameters in Hedonic Price Models." The Journal of Political Economy, 95(1): 81-88.

Bayer, P., R. McMillan, A. Murphy, and C. Timmins. 2010. "A Dynamic Model of Demand for Houses and Neighborhoods." Working Paper, Duke University.

Bishop, K.C., and A.D. Murphy. 2011. "Estimating the Willingness to Pay to Avoid Violent Crime: A Dynamic Approach.” American Economic Review, 101(3): 625-629.

Black, S.E. 1999. "Do Better Schools Matter? Parental Valuation of Elementary Education." Quarterly Journal of Economics, 114(2): 577-599.

Blumstein, A., and J. Wallman. 2006. "The Crime Drop and Beyond." Annual Review of Law and Social Science, 2: 125-146.

Bui, L.T.M., and C.J. Mayer. 2003. "Regulation and Capitalization of Environmental Amenities: Evidence From the Toxic Release Inventory in Massachusetts." Review of Economics and Statistics, 85(3): 693-708.

Chay, K.Y., and M. Greenstone. 2005. "Does Air Quality Matter? Evidence from the Housing Market." Journal of Political Economy, 113(2).

Court, A. T. 1939. "Hedonic Price Indexes with Automotive Examples." In The Dynamics of Automobile Demand. New York: General Motors. 
Davis, L.W. 2004. "The Effect of Health Risk on Housing Values: Evidence from a Cancer Cluster." The American Economic Review, 94(5): 1693-1704.

Ekeland, I., J.J. Heckman, and L. Nesheim. 2004. "Identification and Estimation of Hedonic Models." Journal of Political Economy, 112(1): S60-S109.

Ellickson, B. 1971. "Jurisdictional Fragmentation and Residential Choice." The American Economic Review, 61(2): 334-339.

Epple, D., and G.J. Platt. 1998. "Equilibrium and Local Redistribution in an Urban Economy When Households Differ in Both Preferences and Incomes." Journal of Urban Economics, 43(1): $23-51$.

Epple, D., and R.E. Romano. 1998. "Competition Between Private and Public Schools, Vouchers, and Peer-Group Effects." The American Economic Review, 88(1): 33-62.

Epple, D. 1987. "Hedonic Prices and Implicit Markets: Estimating Demand and Supply Functions for Differentiated Products." The Journal of Political Economy, 95(1): 59-80.

Epple, D., and H. Sieg. 1999. "Estimating Equilibrium Models of Local Jurisdictions." Journal of Political Economy, 107: 645-681.

Epple, D., R. Filimon, and T. Romer. 1984. "Equilibrium Among Local Jurisdictions: Towards an Integrated Approach of Voting and Residential Choice." Journal of Public Economics, 24: 281304.

Figlio, D.N., and M.E. Lucas. 2004. "Whats in a Grade? School Report Cards and the Housing Market." The American Economic Review, 94(3): 591-604.

Gamper-Rabindran, S., R. Mastromonaco, and C. Timmins. 2011. "Valuing the Benefits of Superfund Site Remediation: Three Approaches to Measuring Localized Externalities." NBER Working Paper No. 16655. 
Gayer, T., J.T. Hamilton, and W.K. Viscusi. 2000. "Private Values of Risk Tradeoffs at Superfund Sites: Housing Market Evidence on Learning About Risk." Review of Economics and Statistics, 82(3): 439-451.

Gibbons, S. 2004. "The Costs of Urban Property Crime." The Economic Journal, 114(499): F441F463.

Greenstone, M., and J. Gallagher. 2008. "Does Hazardous Waste Matter? Evidence from the Housing Market and the Superfund Program." The Quarterly Journal of Economics, 123(3): 9511003.

Griliches, Z. 1961. "Hedonic Price Indexes for Automobiles: An Econometric of Quality Change." NBER Chapters - The Price Statistics of the Federal Government: Review, Appraisal, and Recommendations, 173-196.

Heaton, P. 2010. "Hidden in Plain Sight: What the Cost of Crime Research Can Tell Us About Investing in Police." RAND Center on Quality, Occasional Policing Paper.

Heckman, J.J., R.L. Matzkin, and L. Nesheim 2010. "Nonparametric Identification and Estimation of Nonadditive Hedonic Models." Econometrica, 78(5):1569-1591.

Kahn, S., and K. Lang 1988. "Efficient Estimation of Structural Hedonic Systems." International Economic Review, 157-166.

Lancaster, K.J. 1966. "A New Approach to Consumer Theory." The Journal of Political Economy, $74(2): 132-157$.

Levitt, S.D. 2004. "Understanding Why Crime Fell in the 1990s: Four Factors that Explain the Decline and Six that Do Not." The Journal of Economic Perspectives, 18(1): 163-190.

Linden, L., and J.E. Rockoff. 2008. "Estimates of the Impact of Crime Risk on Property Values from Megan's Laws." The American Economic Review, 98(3): 1103-1127. 
Palmquist, R. B. 2005. "Property Value Models." In The Handbook of Environmental Economics. Vol. 2, , ed. K. Goran-Maler and J. R. Vincent. Elsevier.

Parmenter, C.F., and J.C. Pope. 2009. "Quasi-Experiments and Hedonic Property Value Methods." In Handbook on Experimental Economics and the Environment., ed. J. A. List and M. K. Price. Edward Elgar Publishers.

Pope, J.C. 2008. "Buyer Information and the Hedonic: The Impact of a Seller Disclosure on the Implicit Price for Airport Noise." Journal of Urban Economics, 63(2): 498-516.

Rosen, S. 1974. "Hedonic Prices and Implicit Markets: Product Differentiation in Pure Competition." Journal of Political Economy, 82(1): 34.

Sieg, H., V.K. Smith, H.S. Banzhaf, and R. Walsh. 2004. "Estimating the General Equilibrium Benefits of Large Changes in Spatially Delineated Public Goods." International Economic Review, 45: 1047-1077.

Taylor, L.O. 2003. "The Hedonic Method." In A Primer on Nonmarket Valuation of the Environment., ed. T. Brown P. Champ and K. Boyle. Dordrecht: Kluwer Academic Publishers. 